\title{
The horizontal transfer of antibiotic resistance genes is enhanced by ionic liquid with different structure of varying alkyl chain length
}

\author{
Qing Wang 1,2, Qian Lü2, Daqing Mao ${ }^{1 *}$, Yuxiao Cui ${ }^{2}$ and Yi Luo ${ }^{2 *}$
}

OPEN ACCESS

Edited by:

Amy Pruden

Virginia Polytechnic Institute and State

University, USA

Reviewed by:

Etinosa Igbinosa

University of Benin, Nigeria

Pascal Saikaly,

King Abdullah University of Science and Technology, Saudi Arabia

*Correspondence: Daqing Mao,

School of Environmental Science and Engineering, Tianjin University,

Tianjin 300072, China mao@tju.edu.cn;

Yi Luo,

Ministry of Education Key Laboratory of Pollution Processes and Environmental Criteria, College of Environmental Science and Engineering, Nankai University, Tianjin 300071, China luoy@nankai.edu.cn

Specialty section: This article was submitted to Antimicrobials, Resistance and Chemotherapy, a section of the journal Frontiers in Microbiology

Received: 30 April 2015 Accepted: 07 August 2015

Published: 27 August 2015

Citation:

Wang Q, Lu Q, Mao D, Cui Y and Luo Y (2015) The horizontal transfer of antibiotic resistance genes is enhanced by ionic liquid with

different structure of varying alkyl

chain length. Front. Microbiol. 6:864.doi: 10.3389/fmicb.2015.00864
${ }^{1}$ School of Environmental Science and Engineering, Tianjin University, Tianjin, China, ${ }^{2}$ Ministry of Education Key Laboratory of Pollution Processes and Environmental Criteria, College of Environmental Science and Engineering, Nankai University, Tianjin, China

Antibiotic resistance genes (ARGs) have become a global health concern. In our previous study, an ionic liquid (IL) 1-butyl-3-methylimidazolium hexafluorophosphate ([BMIm][PF6]) had been proven to facilitate the dissemination of ARGs in the environment. However, enhanced alkyl group chain length or the substitution of alkyl groups with the cation ring corresponded with increased antimicrobial effects. In this study, we investigated how different structures of ILs with 4,6 , and $8 \mathrm{C}$ atoms in the longer alkyl chain on the imidazolium cations facilitated the dissemination of ARGs. The promotion of plasmid RP4 transfer frequency decreased with [CnMIM][BF4] increasing the alkyl chain length from 4 carbon atoms to 8 carbon atoms on the imidazolium cations, which is observed with [BMIM][BF4] ( $n=4,5.9$ fold) $>$ HMIM][BF4] $(n=6,2.2$ fold) $>[\mathrm{OMIM}][\mathrm{BF} 4](n=8,1.7$ fold). This illustrates that [CnMIM][BF4] with increasing the alkyl chain length exert decreasing ability in facilitating plasmid RP4 horizontal transfer, which is possibly related to IL-structure dependent toxicity. The IL-structure dependent plasmid RP4 transfer frequency was attributable to bacterial cell membrane permeability weaken with increasing alkyl chain length of [CnMIM][PF4], which was evidenced by flow cytometry. In freshwater microcosm, [CnMlm][BF4] promoted the relative abundance of the sull and intl genes for 4.6 folds, aphA and traF for 5.2 folds higher than the untreated groups, promoting the propagation of ARGs in the aquatic environment. This is the first report that ILs with different structure of varying alkyl chain length facilitate horizontal transfer of plasmid RP4 which is widely distributed in the environment, and thus add the adverse effects of the environmental risk of ILs.

Keywords: antibiotic resistance genes, ionic liquid, horizontal transfer, plasmid, environmental risk

\section{Introduction}

Antibiotic resistance genes (ARGs), as the emerging pollutants, have become a global health concern (Pruden et al., 2006, 2013; Mao et al., 2013; Yang et al., 2013). Horizontal gene transfer rather than the accumulation of point mutations play an important role in the propagation and proliferation of ARGs (Aminov, 2011; Dodd, 2012). The critical role played by plasmids in the horizontal transfer of ARGs has been widely recognized, and plasmid is the main vector for 
horizontal transfer of ARGs between environmental bacteria (Sørensen et al., 2005; Zhang et al., 2011; Zhu et al., 2013). Plasmid-mediated horizontal transfer of ARGs to indigenous bacteria was previously reported in soil (Henschke and Schmidt, 1990), activated sludge (Merlin et al., 2011), and wastewater oxidation ponds (Mispagel and Gray, 2005). Dissemination and propagation of ARGs via horizontal transfer from antibiotic resistant bacteria to susceptible strains, either between different species or across genera, mainly occur via conjugation of plasmids (DeBruyn et al., 2011; Qiu et al., 2012). Particularly, in situ transfer of self-transmissible plasmid RP4 which is a 60-kb broad-host-range conjugative plasmid harbors genes for kanamycin resistance $\left(\mathrm{Km}^{\mathrm{R}}\right.$, aphA gene), ampicillin resistance $\left(\mathrm{Ap}^{\mathrm{R}}, \operatorname{tnp} \mathrm{R}\right.$ gene), and tetracycline resistance $\left(\mathrm{Tc}^{\mathrm{R}}\right.$, tet $\mathrm{A}$ gene; Soda et al., 2008).

Ionic liquids (ILs) which are characterized as a big family of compounds with various structures are being considered as "environmental friendly" solvents in modern industry with high polarity and ionic conductivity (Pham et al., 2010), a wide electrochemical window and excellent chemical and thermal stability (Rogers et al., 2002; Zhao et al., 2007). There has not yet been any report of ILs in the environment (Stepnowski, 2005; Markiewicz et al., 2013). However, due to the high water solubility, bioaccumulation, toxicity, and non-biodegradability (Zhu et al., 2009), the ILs have the great potential to increase the risk when they are entering the environment (Zhao et al., 2007; Pham et al., 2010), thus, recent efforts have been toward the potential ecological and environmental risks of ILs (Pham et al., 2010). Adverse effect of some ILs to bacteria are determined by cations (Ganske and Bornscheuer, 2006) and it was found that inhibition effects of Escherichia coli cell growth of various ILs change with the number of $\mathrm{C}$ atoms in the longer alkyl chain (Lee et al., 2005). Enhanced alkyl group chain length or the substitution of alkyl groups with the cation ring corresponded with increased antimicrobial effects (Docherty and Kulpa, 2005). Recent research also revealed that ILs showed higher antimicrobial activity with increasing alkyl chain length (Pernak et al., 2003; Ranke et al., 2004; Docherty and Kulpa, 2005). In our previous study, we demonstrated that the ILs are capable of facilitating the dissemination of ARGs via horizontal gene transfer (Luo et al., 2014). However, how different structures of ILs with various alkyl chain lengths influence on facilitating the dissemination of ARGs has remained unknown.

In this study, ILs 1-altyl-3-methyl imidazolium tetrafluoroborate $\left(\left[\mathrm{C}_{\mathrm{n}} \mathrm{MIM}\right]\left[\mathrm{BF}_{4}\right]\right.$, with 4,6 , and $8 \mathrm{C}$ atoms in the longer alkyl chain (as shown in Table 1), with different structure of varying alkyl chain length were tested for their potential on horizontal transfer of ARGs mediated by plasmid RP4 from the donors (E. coli DH5 $\alpha$ ) to Salmonella (as recipients) in Luria-Bertani (LB) medium and to indigenous bacteria (as recipients) in freshwater microcosms. The effects of bacterial growth and plasmid RP4 horizontal transfer frequency with [CnMIM][BF4] influence of alkyl chain length was determined. Furthermore, alteration of cell membrane permeability with different structure of alkyl chain length by flow cytometry (FCM) was measured to explore a possible mechanism by how the ILs with different structures of alkyl chain length exert
TABLE 1 | Carbon atoms and EC $_{50}$ number of [CnMIM][BF4].

\begin{tabular}{lll}
\hline Name & Acronym & $\begin{array}{l}\text { Carbon atoms in } \\
\text { alkyl chain }(\boldsymbol{n})\end{array}$ \\
\hline $\begin{array}{l}\text { 1-butyl-3-methyl-imidazolium } \\
\text { tetrafluoroborate } \\
\begin{array}{l}\text { 1-hexyl-3-methyl-imidazolium } \\
\text { tetrafluoroborate } \\
\text { 1-octyl-3-methyl-imidazolium } \\
\text { tetrafluoroborate }\end{array}\end{array}$ & {$\left[{\mathrm{BMIM}]\left[\mathrm{BF}_{4}\right]}^{[\mathrm{HMIM}]\left[\mathrm{BF}_{4}\right]}\right.$} & 4 \\
\hline
\end{tabular}

different effects on promoting horizontal transfer of plasmid RP4. To our best knowledge, this is the first study of ILs with different structure of varying alkyl chain length facilitating the dissemination of ARGs in both medium of LB and aquatic microcosm.

\section{Materials and Methods}

\section{ILs Type}

Cationic type of imidazolium (IM) is most widely used in modern industry (Cho et al., 2007; Romero et al., 2008; Zhu et al., 2009) and the 1-alkyl-3-methylimidazolium is one of the most often used IM cations which is attributed to its non-volatility, non-flammability, high thermal stability and an excellent solvent for a wide range of inorganic and organic materials (Gordon, 2001). Anions type of $\mathrm{BF}^{-}{ }^{-}$were most widely used in ILs design (Romero et al., 2008).

The tested ILs in this study were purchased from Chinese Academy of Sciences ( $>99 \%$ pure). They consist of imidazolium cation and anion of $\mathrm{BF}_{4}{ }^{-}$, and cation have two alkyl substituents in positions $\mathrm{R}$ (Figure 1). The ILs 1-alkyl-3methyl imidazolium tetrafluoroborate used in this study were abbreviated [CnMIM][BF4], where $\mathrm{n}$ represent the number of $\mathrm{C}$ atoms in the $\mathrm{R}$ alkyl chain.

\section{Setup of Plasmid RP4 Horizontal Transfer in LB System}

Plasmid RP4 horizontal transfer in LB system was used to determine the effects of ILs [CnMIM][BF4] on the transfer of plasmid RP4 from E. coli $\mathrm{DH} 5 \alpha$ (E. coli $\mathrm{DH} 5 \alpha$, as the donor) to Salmonella ( $\operatorname{Str}^{\mathrm{R}}$, as the recipient, across genera). The strain

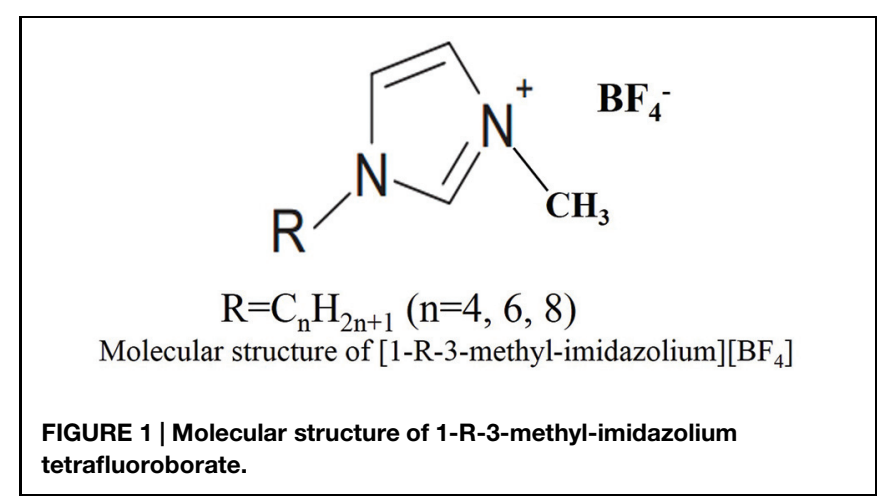


E. coli $\mathrm{DH} 5 \alpha$, harboring the plasmid RP4 carrying ampicillin, kanamycin, and tetracycline resistance genes $\left(\mathrm{Ap}^{\mathrm{R}}, \mathrm{Km}^{\mathrm{R}}\right.$, and $\mathrm{Tc}^{\mathrm{R}}$ ) but no $\operatorname{str}^{\mathrm{R}}$ was used as the donor. The Salmonella carrying $\mathrm{Str}^{\mathrm{R}}$ (in the genome) were used as the recipients and lacked $\mathrm{Ap}^{\mathrm{R}}, \mathrm{Km}^{\mathrm{R}}$, and $\mathrm{Tc}^{\mathrm{R}}$. The system was spiked with the ILs [CnMIM][BF4] of initial concentrations of $0,0.00001,0.0001$, $0.001,0.01,0.1,1.0,2.5,5.0$, and $10.0 \mathrm{~g} / \mathrm{L}$. The IL concentrations in this study were comparable or lower than those in previous toxicity tests (Docherty and Kulpa, 2005; Song et al., 2011; Khudyakov et al., 2012). After mating for $12 \mathrm{~h}$ at $30^{\circ} \mathrm{C}$, DNA was extracted and then traF gene (indicator for plasmid RP4) and 16S rRNA gene were quantified. Transfer frequency $(f)$ was calculated using the formula:

$$
f_{1}=\operatorname{traF} \text { gene }(\text { copies } / \mathrm{mL}) / 16 \mathrm{~S} \mathrm{rRNA}(\text { copies } / \mathrm{mL})
$$

Meanwhile, the number of transconjugants $\left(\mathrm{Ap}^{\mathrm{R}}, \mathrm{Km}^{\mathrm{R}}, \mathrm{Tc}^{\mathrm{R}}\right.$, and $\left.\operatorname{Str}^{\mathrm{R}}\right)\left(\mathrm{N}^{\mathrm{T}}\right)$ were counted and the results were presented as colony forming units per milliliter culture $(\mathrm{cfu} / \mathrm{mL})$. The number of recipients $\left(\mathrm{Str}^{\mathrm{R}}\right)\left(\mathrm{N}_{\mathrm{S}}\right)$ was determined by culturing the bacteria on LB agar plates containing $30 \mathrm{mg} / \mathrm{L}$ of streptomycin $(\mathrm{cfu} / \mathrm{mL})$. Transfer frequency $(f)$ was also calculated using the formula:

$$
f_{2}=\mathrm{N}_{\mathrm{T}}(\mathrm{cfu} / \mathrm{mL}) / \mathrm{N}_{\mathrm{S}}(\mathrm{cfu} / \mathrm{mL})
$$
SI-1.

For details on horizontal transfer experiments, please refer to

\section{Setup of Plasmid RP4 Horizontal Transfer in Freshwater Microcosm}

Setup of plasmid RP4 horizontal transfer in freshwater microcosms was based on the OECD 308 test (OECD, 2002) to test the effects of ILs $[\mathrm{CnMIM}]\left[\mathrm{BF}_{4}\right](n=4,6,8)$ on the plasmid RP4 horizontal transfer to indigenous bacteria in the microcosm. The freshwater sample was collected from the Water Parke $\left(39^{\circ} 6^{\prime} 13^{\prime \prime} \mathrm{N}, 117^{\circ} 9^{\prime} 21^{\prime \prime} \mathrm{E}\right)$ in Tianjin, China on Sep 2013. Water properties are described in Supplementary Table S1. The strain of E. coli DH5 $\alpha$ (plasmid RP4) was used as the RP4 donor strain and donor strain $E$. coli $\mathrm{DH} 5 \alpha$ were tracked by specific primer (E. coli-FW: GTTCATGTGCCATCTGGTCTT; E. coli-RV: AAGTCTTCCTCGGTCGTGAT, Supplementary Table S2). The recipients were indigenous bacteria in freshwater microcosms. Meanwhile, in microcosms, donor isolates were negative in the PCR screening, traF gene (indicator for RP4) and $a p h \mathrm{~A}$ gene (resistant gene to kanamycin on RP4) were negative also in the PCR screening. The microcosms were spiked with an IL [CnMIM][BF4] $(n=4,6,8)$ of initial concentrations of 0 , $0.00001,0.0001,0.001,0.01,0.1,1.0,2.5,5.0$, and 10.0 g/L. Donorfree microcosms also used as controls (no horizontal transfer in donor-free microcosms in pre-experiment). Freshwater microcosms with no added donor and ILs also used as control to exclude mutation. Each concentration was set up in $500 \mathrm{~mL}$ of flask and the experiments lasted for $12 \mathrm{~h}$ at $30^{\circ} \mathrm{C}$, as described in SI-2. Periodic sampling $(10 \mathrm{~mL})$ was collected and was used DNA extraction.

\section{DNA Extraction and Quantitative Polymerase Chain Reaction (qPCR)}

Freshwater microcosm samples $(5 \mathrm{~mL})$ were centrifuged and the total DNA was extracted using a bacterial DNA Kit according to manufacturer's instructions (OMEGA, USA). Quantitative polymerase chain reaction (qPCR) assays were used to quantify the $16 \mathrm{~S}$ rRNA, sul1, int $1, a p h \mathrm{~A}$, and traF genes. Qualitative PCR assays were conducted in a Biometra T100 gradient thermal cycler (Biometra). The qPCR analyses were performed on a Bio-Rad iQ5 instrument to quantify bacteria 16S rRNA, sul1, int $1, a p h \mathrm{~A}$, and $\operatorname{tra\mathrm {F}}$ genes. Calibration standard curves for positive controls were generated as previously described. The establishment of negative and positive controls and qPCR reactions were described previously. The primers, amplification details, and standard curves of the $16 \mathrm{~S}$ rRNA, sul1, int 1, aphA, and traF genes are listed in Supplementary Table S2, SI-3 and SI-4.

\section{Change of Cell Membrane Permeability Measured by Flow Cytometry}

To explore the change of cell membrane permeability induced by [CnMIM][BF4] and the relationship between cell membrane permeability and plasmid RP4 transfer frequency in LB system, FCM (BD FACSCalibur) was applied to differentiate and quantify the [CnMIM][BF4]-treated group and control group cells as a function of the percentage of positive cells based on the extent of cell membrane permeability. Propidium iodide (PI; $1 \mathrm{mg} / \mathrm{mL}$; OMEGA, USA) was used to determine increased membrane permeability cells and control cells. Microcosm samples $(2 \mathrm{~mL})$ were centrifuged and washed $3 \mathrm{x}$ with phosphate buffer solution (PBS). Bacterial cells (the concentration was always less than $10^{6}$ cells $/ \mathrm{mL}$ ) were then stained at concentrations of $10 \mu \mathrm{L}$ PI to $1 \mathrm{~mL}$ of sample, and incubated in the dark for $8 \mathrm{~min}$ before measurement (Xue et al., 2012). The FCM was equipped with an excitation wavelength of $488 \mathrm{~nm}$. All data were processed using CellQuest Pro software (USA).

\section{Results and Discussion}

\section{Structure Dependent of ILs [CnMIM][BF4] Facilitate Plasmid RP4 Transfer}

$[\mathrm{CnMIM}]\left[\mathrm{BF}_{4}\right](n=4,6,8)$ promoted the plasmid RP4 transfer with dose-effect in freshwater microcosms and LB medium (Figure 2). The plasmid RP4 transfer frequency enhanced with increasing [CnMIM][BF4] concentrations, however, decreased when concentration is higher than $1.0 \mathrm{~g} / \mathrm{L}$ for [BMIM][BF4], $0.01 \mathrm{~g} / \mathrm{L}$ for [HMIM][BF4], and $0.0001 \mathrm{~g} / \mathrm{L}$ for [OMIM][BF4]. Meanwhile, the dose-effect dependent of ILs [CnMIM][BF4] facilitating plasmid RP4 transfer associated with ILs' effects on bacterial growth. In this study, the significant dose-effect inhibition was observed between the bacteria concentrations (the optical densities of $\left.\mathrm{OD}_{600}\right)$ and the concentrations of each of the compound ([CnMIM] $\left[\mathrm{BF}_{4}\right]$; Figure 3 and Supplementary Figure S2B).

Additionally, [CnMIM][BF4] promoted the plasmid RP4 transfer with significant structure-activity both in LB medium 

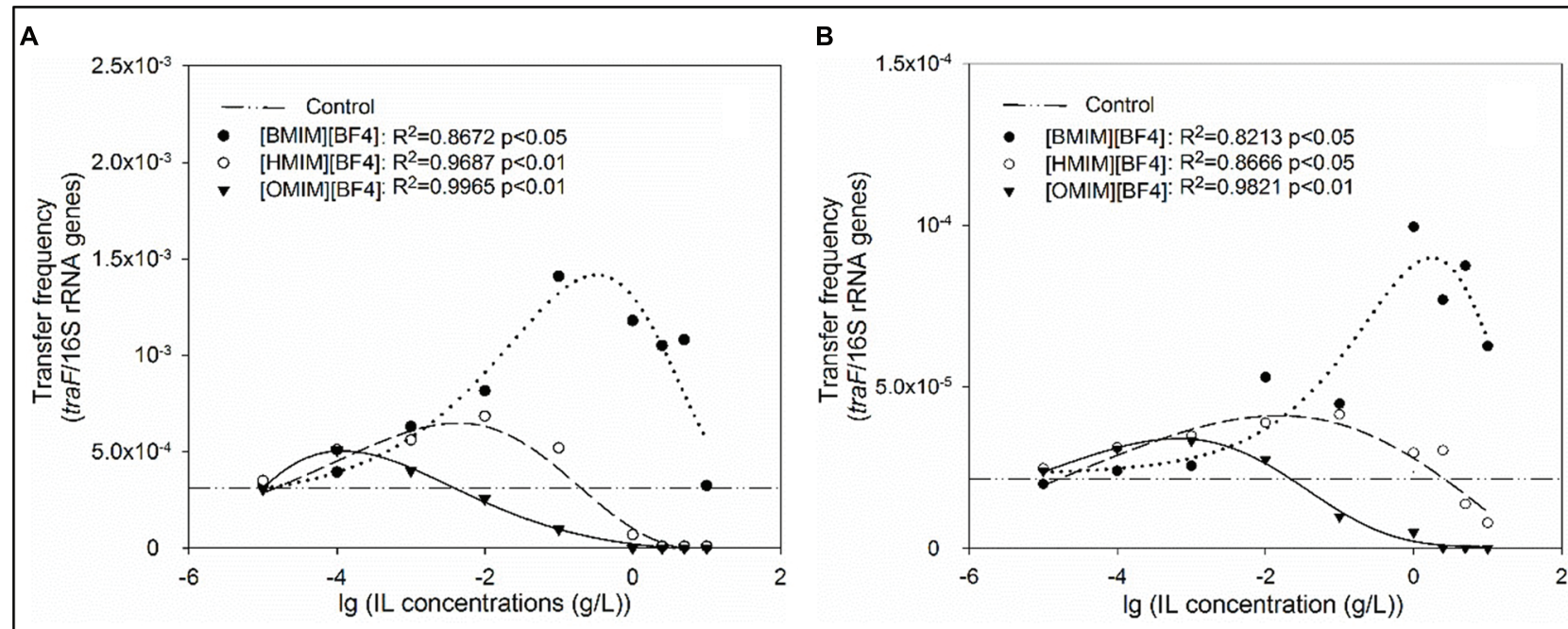

FIGURE 2 | Influence of alkyl chain length with different concentrations of ILs $(0,0.00001,0.0001,0.001,0.01,0.1,1.0,2.5,5.0$, and $10.0 \mathrm{~g} / \mathrm{L})$ on plasmid transfer frequency in freshwater microcosms (A) and in LB system (B) at mating for $\mathbf{1 2} \mathbf{h}$. The transfer frequency was based on formula (1), $f_{1}=$ traF gene (copies $/ \mathrm{mL}$ )/16S rRNA (copies/mL). ([BMIM][BF4], $n=4$; [HMIM][BF4], $n=6$; [OMIM][BF4], $n=8$.)
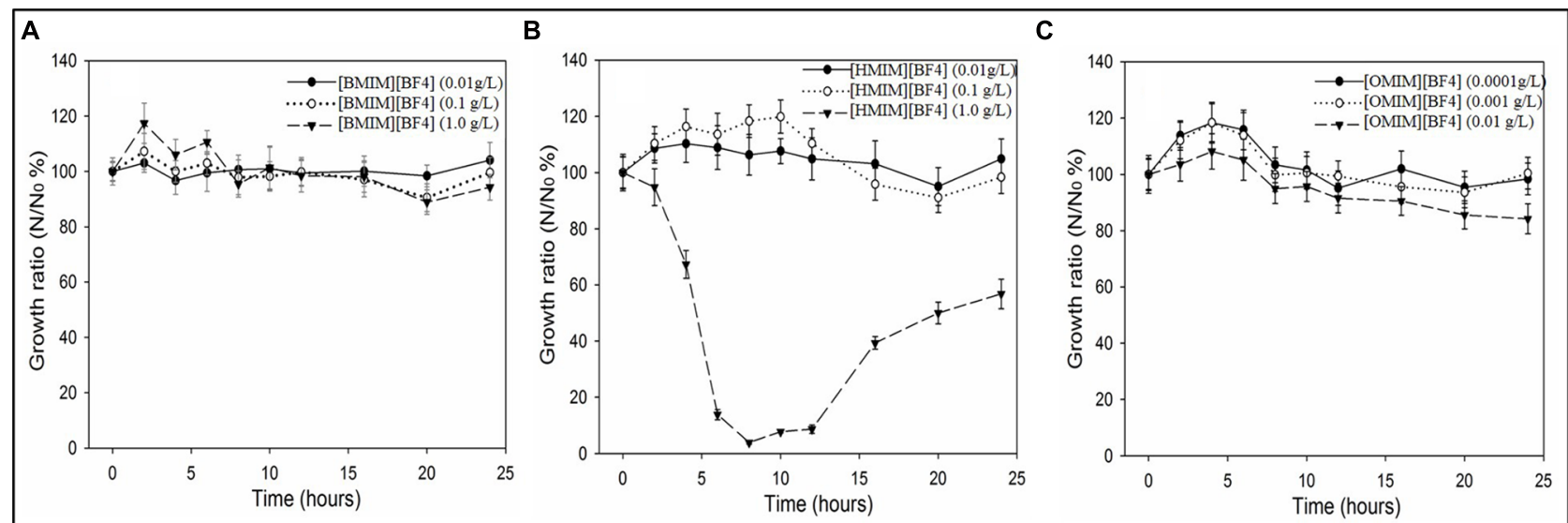

FIGURE 3 | Growth ratio (N/No, \%) of Escherichia coli DH5 $\alpha$ in LB system treated with [CnMIM][BF4]. (A) [BMIM][BF4] (concentration of 0.01, 0.1, $1.0 \mathrm{~g} / \mathrm{L}$ ); (B) [HMIM][BF4] (concentration of 0.01, 0.1, $1.0 \mathrm{~g} / \mathrm{L}$ ); (C) [OMIM][BF4] (concentration of 0.0001, 0.001, 0.01g/L). Control: untreated with [CnMIM][BF4]. ([BMIM] [BF4], $n=4$; [HMIM][BF4], $n=6$; [OMIM] [BF4], $n=8$ ).

and freshwater microcosms (Figure 2 and Supplementary Figure S1). The promotion of plasmid RP4 transfer frequency decreased with [CnMIM][BF4] increasing the alkyl chain length from 4 carbon atoms to 8 carbon atoms on the imidazolium cations, which is observed with [BMIM][BF4] $(n=4,5.9$ fold $)>\operatorname{HMIM}][\mathrm{BF} 4](n=6,2.2$ fold $)>$ [OMIM] [BF4] $(n=8$, 1.7 fold). This illustrates that [CnMIM][BF4] with increasing the alkyl chain length exert decreasing ability in facilitating plasmid RP4 horizontal transfer, which is possibly related to their structure dependent toxicity differences. The size and charge distribution of the individual ions mainly affects the properties of an IL (Wilkes, 2004). Matsumoto et al. (2004) assessed the toxicity of [CnMIM][PF6] $(n=4,6,8)$ to the lactic acid-producing of microorganism Lactobacillus and found that the production activity of this microorganism decreased with increasing alkyl chain length on the imidazolium cations. Meanwhile, the structure-activity also associated with ILs effects on bacterial growth and enhanced inhibition of bacterial growth with increasing alkyl chain with [CnMIM] [BF4] treated in LB system. In this study, the significant structure-activity between the microbial concentrations (the optical densities of $\mathrm{OD}_{600}$ ) and $[\mathrm{CnMIM}]\left[\mathrm{BF}_{4}\right]$ alkyl chain length in position $\mathrm{R}$ were also found (Figure 3). The inhibition concentrations of growth of E. coli. DH5 $\alpha$ for different structures of [CnMIM][BF4] is largely different, it is larger than $2.5 \mathrm{~g} / \mathrm{L}$ for $[\mathrm{BMIM}]\left[\mathrm{BF}_{4}\right]$ $(n=4), 1.0 \mathrm{~g} / \mathrm{L}$ for [HMIM] [BF4] $(n=6)$, and $0.1 \mathrm{~g} / \mathrm{L}$ for 
[OMIM][BF4] $(n=8)$. Additionally, in this study, the ILs inhibition capability for bacterial growth was [BMIM][BF4] $(n=4)<[\mathrm{HMIM}][\mathrm{BF} 4](n=6)<[\mathrm{OMIM}][\mathrm{BF} 4](n=8)$ with the same concentration (e.g., $1.0 \mathrm{~g} / \mathrm{L}$ ), which attributed to more toxic of ILs with longer alkyl chains on the cations (Docherty and Kulpa, 2005; Ganske and Bornscheuer, 2006). A relationship between the length of alkyl chain and antimicrobial activities was also found and ILs with short alkyl chain substituent are not active against bacteria and fungi, in contrast ILs containing 10, 11,12 , and 14 carbon atoms in the alkyl chain show very high antimicrobial activities (Pernak et al., 2003; Nancharaiah et al., 2012).

Most interestingly, ILs [CnMIM][BF4] with concentrations of enhancing plasmid RP4 transfer have no influence on bacterial growth. In this study, growth of E. coli. $\mathrm{DH} 5 \alpha$ were not influenced when $[\mathrm{CnMIM}]\left[\mathrm{BF}_{4}\right]$ concentrations are less than $1.0 \mathrm{~g} / \mathrm{L}$ for [BMIM][BF4], $0.01 \mathrm{~g} / \mathrm{L}$ for [HMIM][BF4], and $0.0001 \mathrm{~g} / \mathrm{L}$ for $[\mathrm{OMIM}][\mathrm{BF} 4]$ (Figure 3). Consistently, the promotion effect on plasmid RP4 transfer is most obvious when the ILs concentrations are fall in the same range (less than $1.0 \mathrm{~g} / \mathrm{L}$ for [BMIM][BF4], $0.01 \mathrm{~g} / \mathrm{L}$ for [HMIM][BF4], and $0.0001 \mathrm{~g} / \mathrm{L}$ for $[\mathrm{OMIM}][\mathrm{BF} 4])$. Bacterial concentration plays a crucial role in the plasmid horizontal transfer. In this study, the observed highest values of plasmid transfer frequency were all based on the ILs concentration with no significant inhibition for bacterial growth. Therefore, special attention needs to be paid for ILs [CnMIM][BF4] with concentration especially below the sublethal concentration in the environment, this increase the risk of ILs facilitating the transmission and proliferation of multiresistance media by plasmid RP4 through horizontal transfer among microorganisms in aquatic environment, and thus posing great risks to public health.

\section{Structure Dependent of ILs [CnMIM][BF4] Increased Cell Membrane Permeability}

A positive correlation $\left(r^{2}=0.682, p<0.05\right.$, Figure $\left.4 \mathbf{H}\right)$ was found between cell membrane permeability and plasmid RP4 transfer frequency, indicating that enhanced plasmid RP4 transfer could be attributed to increased cell membrane permeability. Meanwhile, FCM assays of microorganisms showed that the percentage of PI-positive cells decreased with increasing alkyl chain length of [CnMIM][PF4], indicating the ability of ILs enhancing bacterial cell membrane permeability weaken with increasing alkyl chain length of [CnMIM][PF4] (Figure 4). In the concentration of highest plasmid RP4 transfer frequency, cell membrane permeability increased by 2 -fold treated with $[\mathrm{BMIM}]\left[\mathrm{BF}_{4}\right](n=4$; Figure 4B, 84.59\%) compared with untreated bacteria (Figure 4A, 43.58\%). The cell membrane permeability increased by 1.27 and 1.24 folds treated with [HMIM] $\left[\mathrm{BF}_{4}\right]\left(n=6\right.$; Figure 4D, 55.55\%) and [OMIM] $\left[\mathrm{BF}_{4}\right]$ ( $n=8$; Figure $4 \mathrm{~F}, 54.28 \%$ ). The capability of ILs enhancing cell membrane permeability follow the order of $[\mathrm{BMIM}]\left[\mathrm{BF}_{4}\right]$

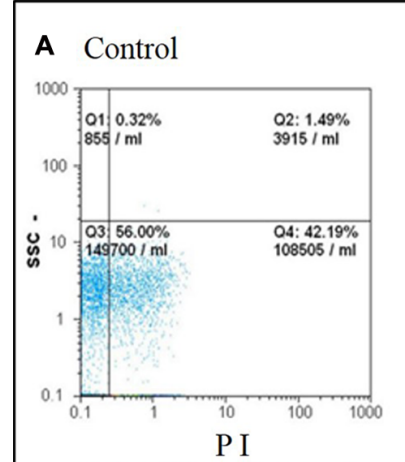

E $[\mathrm{HMIM}][\mathrm{BF} 4](0.1 \mathrm{~g} / \mathrm{L})$

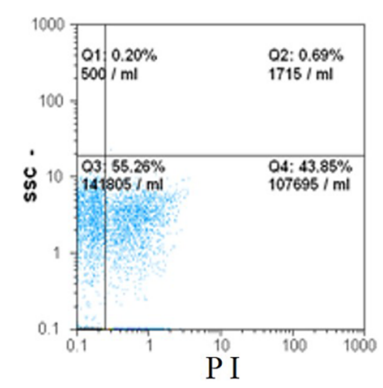

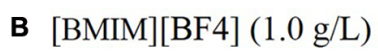

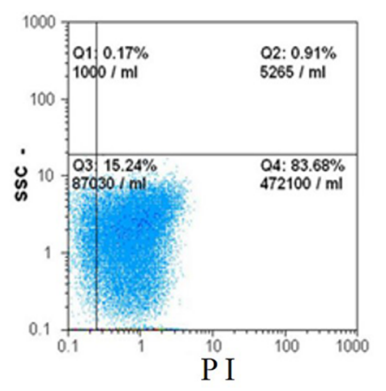

F $[\mathrm{OMIM}][\mathrm{BF} 4](0.0001 \mathrm{~g} / \mathrm{L})$

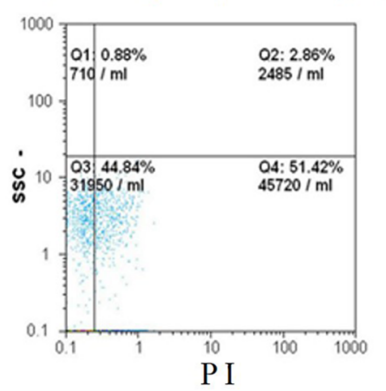

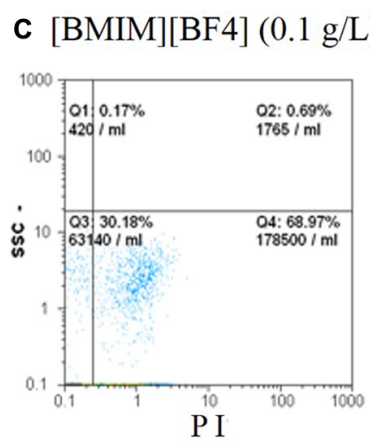

G $[\mathrm{OMIM}][\mathrm{BF} 4](0.01 \mathrm{~g} / \mathrm{L})$

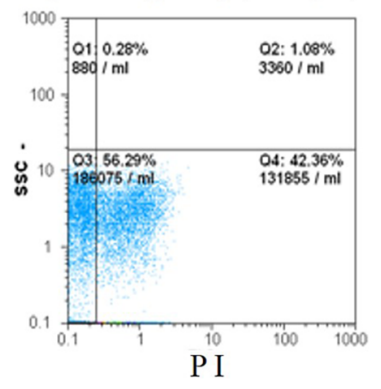

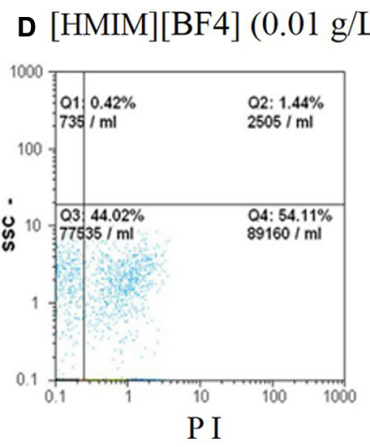

H

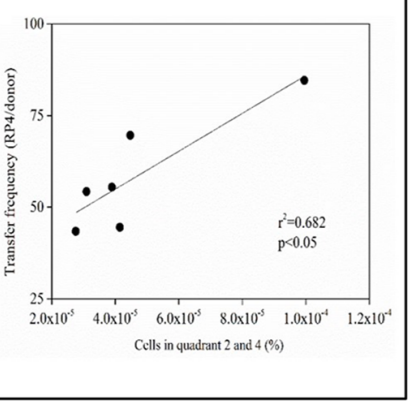

FIGURE 4 | Cell membrane permeability of microorganisms in LB system treated with [CnMIM][BF4] under the concentration that the highest plasmid RP4 transfer frequency quantified using flow cytometry. Flow cytometry data in dot plot: Quadrant 1 and 3: negative signal (normal cells); Quadrant 2 and 4: PI positive (cells with increased cell membrane permeability).

(A) Control: untreated with [CnMIM][BF4]. (B,C): [BMIM][BF4]; (D,E): [HMIM][BF4]; (F,G): [OMIM][BF4]. (H) Correlation between transfer frequency in LB system with percentage of cells with increased cell membrane permeability (PI positive) in the total cells treated with [CnMIM][BF4]. ([BMIM][BF4], $n=4$; [HMIM][BF4], $n=6$; [OMIM][BF4], $n=8$.) 
$(n=4)>[\mathrm{HMIM}]\left[\mathrm{BF}_{4}\right](n=6)>[\mathrm{OMIM}]\left[\mathrm{BF}_{4}\right](n=8)$ which is the same as the order of ILs enhancing plasmid RP4 transfer frequency.

Cell membranes are selective semi-permeable membrane and constitute a barrier for horizontal transfer of genetic information among bacteria. Increased cell membrane permeability induced by ILs [CnMIM][PF4] could suppress cell membrane barrier and contribute to genetic information between cells (Thomas and Nielsen, 2005; Alekshun and Levy, 2007). ILs with imidazolium show similar structure to cationic surfactants (Markiewicz et al., 2013), which are known as amphiphilic compounds that contain ionic group and non-polar residues and can increase cell membrane permeability. In this study, the IL [OMIM][BF4] $(n=8)$ contribute to adsorb onto bacterial surface and damage the cell membrane, thereby assisting suppressed cell membrane barrier by increased cell membrane permeability (Thomas and Nielsen, 2005; Alekshun and Levy, 2007). In this study, the maximum horizontal transfer frequency facilitated by $1.0 \mathrm{~g} / \mathrm{L}$ of $[\mathrm{BMIm}][\mathrm{BF} 4]$ was attributed to the highest cell membrane permeability.

\section{ILs Facilitated Dissemination of ARGs in Freshwater Microcosms}

In freshwater microcosms, [CnMIm] $\left[\mathrm{BF}_{4}\right](n=4,6,8)$ promoted the relative abundance of the sulI (sulI gene/16S rRNA gene) and int $\mathrm{I}$ (intI gene/16S rRNA gene) genes for 4.6 folds versus that of the untreated controls (Figure 5A; $p<0.05, \mathrm{~S}-\mathrm{N}-\mathrm{K}$ test). Meanwhile, a positive correlation $\left(r^{2}=0.577, p<0.05\right)$ was found between relative abundance of the sulI and intI genes (Figure 5B), implying that the proliferation and propagation of sulI gene were primarily attributable to facilitation by class I integrons. The cassette consists of three parts: $5^{\prime}$ conserved segment ( $5^{\prime}$ CS), $3^{\prime}$ conserved segment ( $3^{\prime}$ CS) and the variable region between them (Rowe-Magnus et al., 2001). $3^{\prime}$ conserved segment includes two genes that encoding resistance, sulI (encoding sulfanilamide resistance) and qacE $\triangle 1$ (encoding quaternary ammonium salt compounds and ethidium bromine resistance). Variable region harbor different number of gene cassettes, which were used to encode drug-resistance (Sunde, 2005). The propagation of sulI, qacE $\triangle 1$, and ARGs in gene cassette were facilitated by class 1 integrons, which may exhibit

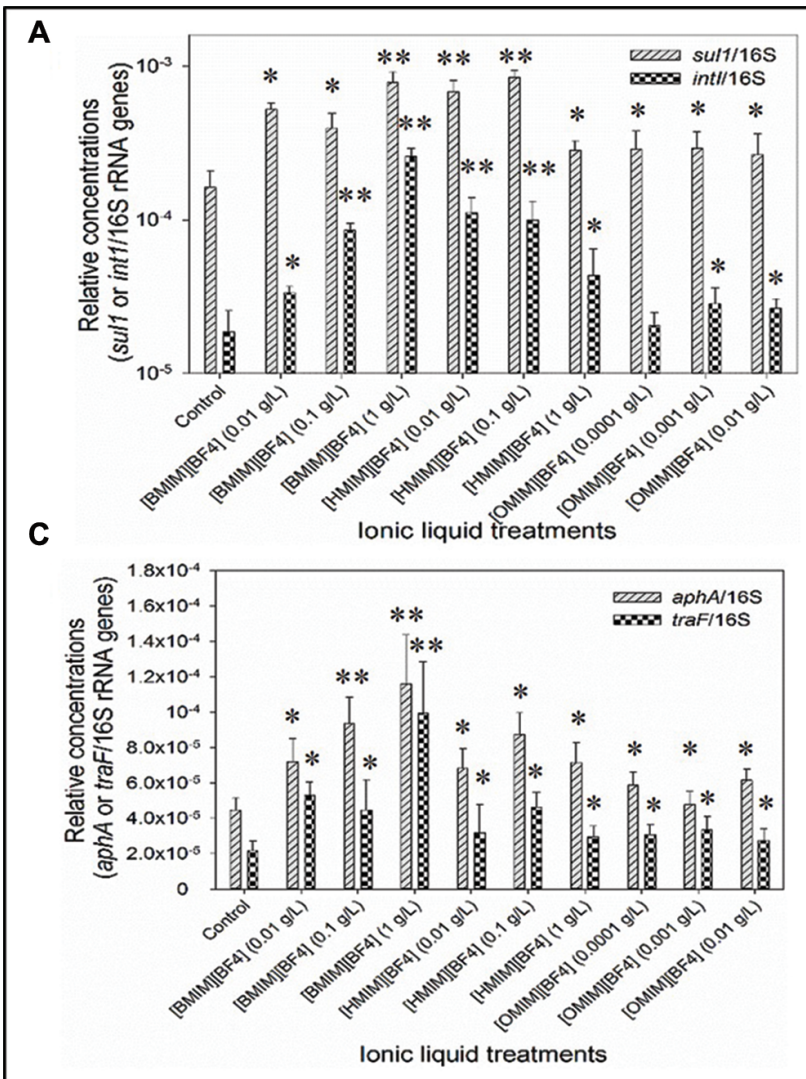

FIGURE 5 | The relative abundances of sul1 gene (sul1/16S rRNA) and int 1 gene (int1/16S rRNA; A), and correlation between relative abundance of sul1 gene (sul1/16S rRNA) versus relative abundance of int1 gene (int1/16S rRNA; B); the relative abundances of aphA gene (aphA/16S rRNA) and traF gene (traF/16S rRNA; C), and correlation between relative abundance of aphA gene (aphA/16S rRNA) versus traF gene (traF/16S rRNA; D) in the freshwater microcosms treated with
B

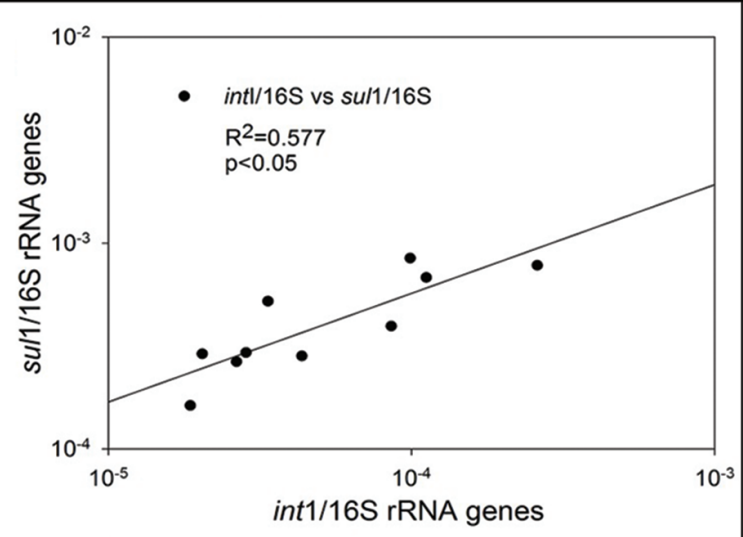

D

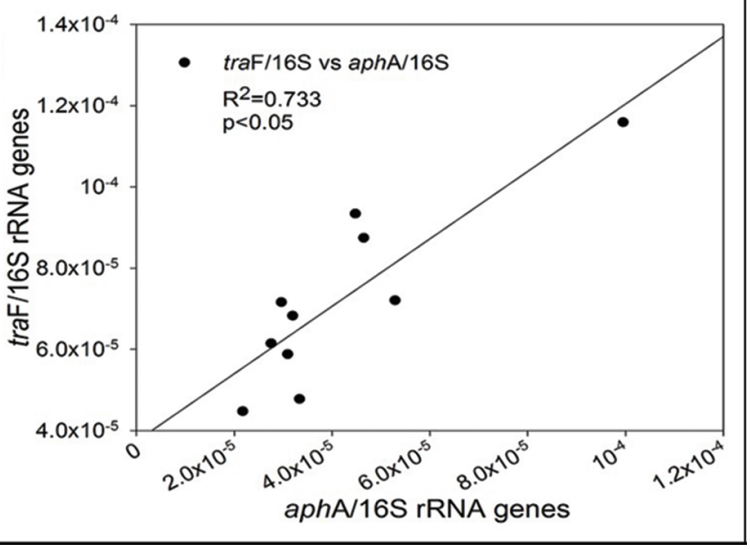

[CnMIM][BF4] (0.01, 0.1, 1.0 g/L). ([BMIM][BF4], $n=4$; [HMIM][BF4], $n=6$; [OMIM][BF4], $n=8$.) The concentration of [CnMIM][BF4] $(0.01,0.1,1.0 \mathrm{~g} / \mathrm{L}) \mathrm{had}$ a significant effect on the dissemination of ARGs in freshwater microcosms (ANOVA, $p<0.05$ ). Significant differences between each of the IL treated groups and the control $(0 \mathrm{~g} / \mathrm{L}$ of $\mathrm{IL})$ were tested with the

Student-Newman-Keuls $(\mathrm{S}-\mathrm{N}-\mathrm{K})$ test, and showed with $\left({ }^{*} p<0.05\right)$ and $(* * p<0.01)$. 
enhanced propagation characteristics compared to other mobile genetic elements. Additionally, microbial concentrations (16SrRNA level) were not significantly change in the microcosm (Figure 3). This suggested that rather than bacterial growth, the enhanced the abundance of ARGs was attributable to the dissemination and propagation of ARGs within the cassette of class I integrons.

Meanwhile, $[\mathrm{CnMIm}]\left[\mathrm{BF}_{4}\right](n=4,6,8)$ facilitated the relative abundance of $a p h \mathrm{~A}(a p h \mathrm{~A} / 16 \mathrm{~S}$ rRNA genes) and traF (traF/16S rRNA genes), and up to 5.2 folds higher than the untreated controls (Figure 5C; $p<0.05, \mathrm{~S}-\mathrm{N}-\mathrm{K}$ test). A significant correlation $\left(r^{2}=0.733, p<0.05\right.$; Figure 5D) was also found between the relative abundance of $a p h \mathrm{~A}$ and $\operatorname{traF}$ genes, which implies that increased in ARGs were attributable to elevated plasmid RP4 horizontal transfer promoted by ILs [CnMIm] $\left[\mathrm{BF}_{4}\right]$. Meanwhile, [BMIm][PF6] exposure did not influence the donors ratio (Supplementary Figure S2A) and 16S rRNA ratio (microbial concentrations, Supplementary Figure S2B), implying that the [BMIm][PF6]-facilitated transfer of class I integrons or plasmid RP4 were not attributed to an increased total bacterial abundance. Plasmids play a critical role in horizontal gene transfer for the spread and dissemination of ARGs in the environment (Zatyka and Thomas, 1998; Sørensen et al., 2005). In this study, plasmid RP4 harbors multi-resistance genes of aphA gene (kanamycin resistance), $t n p \mathrm{R}$ gene (ampicillin resistance), and tet $\mathrm{A}$ gene (tetracycline resistance; Soda et al., 2008), thus, ILs [CnMIm] $\left[\mathrm{BF}_{4}\right]$ exert a different enhanced selective pressure to increase levels of plasmid RP4 through horizontal transfer among microorganism, promoting the propagation of ARGs in the environment. Furthermore, excellent stability makes some ILs conceivable into wastewater treatment plants, and discharged into the aquatic environment (Pham et al., 2010). As consequent, ILs can represent a continuous selective pressure to promote the dissemination and propagation of ARGs.

\section{References}

Alekshun, M. N., and Levy, S. B. (2007). Molecular mechanisms of antibacterial multidrug resistance. Cell 128, 1037-1050. doi: 10.1016/j.cell.2007.03.004

Aminov, R. I. (2011). Horizontal gene exchange in environmental microbiota. Front. Microbiol. 2:158. doi: 10.3389/fmicb.2011.00158

Cho, C. W., Pham, T. P., Jeon, Y. C., Vijayaraghavan, K., Choe, W. S., and Yun, Y.S. (2007). Toxicity of imidazolium salt with anion bromide to a phytoplankton Selenastrum capricornutum: effect of alkyl-chain length. Chemosphere 69, 1003-1007. doi: 10.1016/j.chemosphere.2007.06.023

DeBruyn, J. M., Mead, T. J., and Sayler, G. S. (2011). Horizontal transfer of PAH catabolism genes in Mycobacterium: evidence from comparative genomics and isolated pyrene-degrading bacteria. Environ. Sci. Technol. 46, 99-106. doi: $10.1021 /$ es201607y

Docherty, K. M., and Kulpa, C. F. Jr. (2005). Toxicity and antimicrobial activity of imidazolium and pyridinium ionic liquids. Green Chem. 7, 185-189. doi: 10.1039/b419172b

Dodd, M. C. (2012). Potential impacts of disinfection processes on elimination and deactivation of antibiotic resistance genes during water and wastewater treatment. J. Environ. Monit. 14, 1754-1771. doi: 10.1039/c2em0 $0006 \mathrm{~g}$

Ganske, F., and Bornscheuer, U. T. (2006). Growth of Escherichia coli, Pichia pastoris and Bacillus cereus in the presence of the ionic liquids [BMIM][BF4] and [BMIM][PF6] and organic solvents. Biotechnol. Lett. 28, 465-469. doi: 10.1007/s10529-006-0006-7

\section{Conclusion}

In this study, ILs exerts a selective pressure to facilitate the spread of antibiotic resistance through plasmid RP4 horizontal transfer among bacteria, promoting increasing levels of the sulI, intI, $a p h \mathrm{~A}, \operatorname{tra\mathrm {F}}$ genes in aquatic environment. Meanwhile, the peak transfer frequency of promotion of plasmid RP4 transfer were decreased in different degrees with [CnMIM] [BF4] $(n=4,6,8)$ increasing the alkyl chain length, which attributed to bacterial cell membrane permeability weaken with increasing alkyl chain length of [CnMIM][PF4]. Therefore, in a long period, residual $[\mathrm{CnMIM}][\mathrm{BF} 4]$ in aquatic environment has the great potential to promote the spread of antibiotic resistance. These findings suggest that ILs proposed for use in industrial processes should be carefully evaluated for their ecological and environmental risks before they are discharged into the environment.

\section{Acknowledgments}

We express our sincerest thanks to Professor Junwen Li (Institute of Health and Environmental Medicine, Key Laboratory of Risk Assessment and Control for Environment \& Food Safety, Tianjin in China) for provision of the RP4 plasmid. This work was financially supported by the National Natural Science Foundation of China $(21277075,31270542$, 31470440), the State Environmental Protection Commonweal Project (201309031).

\section{Supplementary Material}

The Supplementary Material for this article can be found online at: http://journal.frontiersin.org/article/10.3389/fmicb. 2015.00864

Gordon, C. M. (2001). New developments in catalysis using ionic liquids. Appl. Catal. A Gen. 222, 101-117. doi: 10.1016/S0926-860X(01)00834-1

Henschke, R. B., and Schmidt, F. R. J. (1990). Plasmid mobilization from genetically engineered bacteria to members of the indigenous soil microflora in situ. Curr. Microbiol. 20, 105-110. doi: 10.1007/BF020 92881

Khudyakov, J. I., D’Haeseleer, P., Borglin, S. E., Deangelis, K. M., Woo, H., Lindquist, E. A., et al. (2012). Global transcriptome response to ionic liquid by a tropical rain forest soil bacterium, Enterobacter lignolyticus. Proc. Natl. Acad. Sci. U.S.A. 109, 2173-2182. doi: 10.1073/pnas.1112750109

Lee, S.-M., Chang, W.-J., Choi, A.-R., and Koo, Y. M. (2005). Influence of Ionic Liquids on the Growth of Escherichia coli (Short Communication). Korean J. Chem. Eng. 22, 687-690. doi: 10.1007/BF02705783

Luo, Y., Wang, Q., Lu, Q., Mu, Q., and Mao, D. (2014). An ionic liquid facilitates the proliferation of antibiotic resistance genes mediated by class I integrons. Environ. Sci. Technol. Lett. 1, 266-270. doi: 10.1021/ez5 $00103 \mathrm{v}$

Mao, D., Luo, Y., Mathieu, J., Wang, Q., Feng, L., Mu, Q. H., et al. (2013). Persistence of extracellular DNA in river sediment facilitates antibiotic resistance gene propagation. Environ. Sci. Technol. 48, 71-78. doi: $10.1021 /$ es404280v

Markiewicz, M., Jungnickel, C., and Arp, H. P. H. (2013). Ionic liquid assisted dissolution of dissolved organic matter and PAHs from soil below the critical micelle concentration. Environ. Sci. Technol. 47, 6951-6958. doi: $10.1021 /$ es304568w 
Matsumoto, M., Mochiduki, K., and Kondo, K. (2004). Toxicity of ionic liquids and organic solvents to lactic acid-producing bacteria. J. Biosci. Bioeng. 98, 344-347. doi: $10.1263 /$ jbb. 98.344

Merlin, C., Bonot, S., Courtois, S., and Block, J. C. (2011). Persistence and dissemination of the multiple-antibiotic-resistance plasmid pB10 in the microbial communities of wastewater sludge microcosms. Water Res. 45, 2897-2905. doi: 10.1016/j.watres.2011.03.002

Mispagel, H., and Gray, J. T. (2005). Antibiotic resistance from wastewater oxidation ponds. Water Environ. Res. 77, 2996-3002. doi: 10.2175/106143005X73901

Nancharaiah, Y. V., Reddy, G. K. K., Lalithamanasa, P., and Venugopalan, V. P. (2012). The ionic liquid 1-alkyl-3-methylimidazolium demonstrates comparable antimicrobial and antibiofilm behavior to a cationic surfactant. Biofouling 28, 1141-1149. doi: 10.1080/08927014.2012.736966

OECD. (2002). Aerobic and Anaerobic Transformation in Aquatic Sediment Systems, OECD Guidelines for the Testing of Chemicals, Section 3. Paris: OECD Publishing.

Pernak, J., Sobaszkiewicz, K., and Mirska, I. (2003). Anti-microbial activities of ionic liquids. Green Chem. 5, 52-56. doi: 10.1039/b207543c

Pham, T. P., Cho, C. W., and Yun, Y. S. (2010). Environmental fate and toxicity of ionic liquids: a review. Water Res. 44, 352-372. doi: 10.1016/j.watres.2009.09.030

Pruden, A., Larsson, D. G., Amezquita, A., Collignon, P., Brandt, K. K., Graham, D. W., et al. (2013). Management options for reducing the release of antibiotics and antibiotic resistance genes to the environment. Environ. Health Perspect. 121, 878-885. doi: 10.1289/ehp.1206446

Pruden, A., Pei, R. T., Storteboom, H., and Carlson, K. H. (2006). Antibiotic resistance genes as emerging contaminants: studies in northern Colorado. Environ. Sci. Technol. 40, 7445-7450. doi: 10.1021/es0604131

Qiu, Z., Yu, Y., Chen, Z., Jin, M., Yang, D., Zhao, Z., et al. (2012). Nanoalumina promotes the horizontal transfer of multiresistance genes mediated by plasmids across genera. Proc. Natl. Acad. Sci. U.S.A. 109, 4944-4949. doi: 10.1073/pnas.1107254109

Ranke, J., Mölter, K., Stock, F., Bottin-Weber, U., Poczobutt, J., Hoffmann, J., et al. (2004). Biological effects of imidazolium ionic liquids with varying chain lengths in acute Vibrio fischeri and WST-1 cell viability assays. Ecotoxicol. Environ. Saf. 58, 396-404. doi: 10.1016/S0147-6513(03) 00105-2

Rogers, R. D., Seddon, K. R., and Volkov, S. (2002). Green Industrial Applications of Ionic Liquids: NATO Science Series II. New York: Springer.

Romero, A., Santos, A., Tojo, J., and Rodriguez, A. (2008). Toxicity and biodegradability of imidazolium ionic liquids. J. Hazard. Mater. 151, 268-273. doi: 10.1016/j.jhazmat.2007.10.079

Rowe-Magnus, D. A., Guerout, A. M., Ploncard, P., Dychinco, B., Davies, J., and Mazel, D. (2001). The evolutionary history of chromosomal super-integrons provides an ancestry for multiresistant integrons. Proc. Natl. Acad. Sci. U.S.A. 98, 652-657. doi: 10.1073/pnas.98.2.652

Soda, S., Otsuki, H., Inoue, D., Tsutsui, H., Sei, K., and Ike, M. (2008). Transfer of antibiotic multiresistant plasmid RP4 from Escherichia coli to activated sludge bacteria. J. Biosci. Bioeng. 106, 292-296. doi: 10.1263/jbb.106.292
Song, X. L., Ye, S. Y., Xie, R., Yin, L., Shi, X., and Luo, S. C. (2011). Effects of bmim [PF6] treatments with different concentrations on microbial activity of Saccharomyces cerevisiae. Korean J. Chem. Eng. 28, 1902-1907. doi: 10.1007/s11814-011-0076-7

Sørensen, S. J., Bailey, M., Hansen, L. H., Kroer, N., and Wuertz, S. (2005). Studying plasmid horizontal transfer in situ: a critical review. Nat. Rev. Microbiol. 3, 700-710. doi: 10.1038/nrmicro1232

Stepnowski, P. (2005). Solid-phase extraction of room-temperature imidazolium ionic liquids from aqueous environmental samples. Anal. Bioanal. Chem. 381, 189-193. doi: 10.1007/s00216-004-2932-3

Sunde, M. (2005). Prevalence and characterization of class 1 and class 2 integrons in Escherichia coli isolated from meat and meat products of Norwegian origin. J. Antimicrob. Chemother. 56, 1019-1024. doi: 10.1093/jac/dki377

Thomas, C. M., and Nielsen, K. M. (2005). Mechanisms of, and barriers to, horizontal gene transfer between bacteria. Nat. Rev. Microbiol. 3, 711-721. doi: $10.1038 /$ nrmicro1234

Wilkes, J. S. (2004). Properties of ionic liquid solvents for catalysis. J. Mol. Catal. A Chem. 214, 11-17. doi: 10.1016/j.molcata.2003.11.029

Xue, Z., Sendamangalam, V. R., Gruden, C. L., and Seo, Y. (2012). Multiple roles of extracellular polymeric substances on resistance of biofilm and detached clusters. Environ. Sci. Technol. 46, 13212-13219. doi: 10.1021/es3031165

Yang, Y., Li, B., Ju, F., and Zhang, T. (2013). Exploring variation of antibiotic resistance genes in activated sludge over a four-year period through a metagenomic approach. Environ. Sci. Technol. 47, 10197-10205. doi: $10.1021 /$ es4017365

Zatyka, M., and Thomas, C. M. (1998). Control of genes for conjugative transfer of plasmids and other mobile elements. FEMS Microbiol. Rev. 21, 291-319. doi: 10.1111/j.1574-6976.1998.tb00355.x

Zhang, T., Zhang, X. X., and Ye, L. (2011). Plasmid metagenome reveals high levels of antibiotic resistance genes and mobile genetic elements in activated sludge. PLoS ONE 6:e26041. doi: 10.1371/journal.pone.0026041

Zhao, D., Liao, Y., and Zhang, Z. (2007). Toxicity of ionic liquids. Clean (Weinh.) 35, 42-48. doi: 10.1002/clen.200600015

Zhu, S., Chen, R., Wu, Y., Chen, Q., Zhang, X., and Yu, Z. (2009). A mini-review on greenness of ionic liquids. Chem. Biochem. Eng. Q. 23, 207-211.

Zhu, Y. G., Johnson, T. A., Su, J. Q., Qiao, M., Guo, G. X., Stedtfeld, R. D., et al. (2013). Diverse and abundant antibiotic resistance genes in Chinese swine farms. Proc. Natl. Acad. Sci. U.S.A. 110, 3435-3440. doi: $10.1073 /$ pnas. 1222743110

Conflict of Interest Statement: The authors declare that the research was conducted in the absence of any commercial or financial relationships that could be construed as a potential conflict of interest.

Copyright (C) 2015 Wang, Lu, Mao, Cui and Luo. This is an open-access article distributed under the terms of the Creative Commons Attribution License (CC BY). The use, distribution or reproduction in other forums is permitted, provided the original author(s) or licensor are credited and that the original publication in this journal is cited, in accordance with accepted academic practice. No use, distribution or reproduction is permitted which does not comply with these terms. 